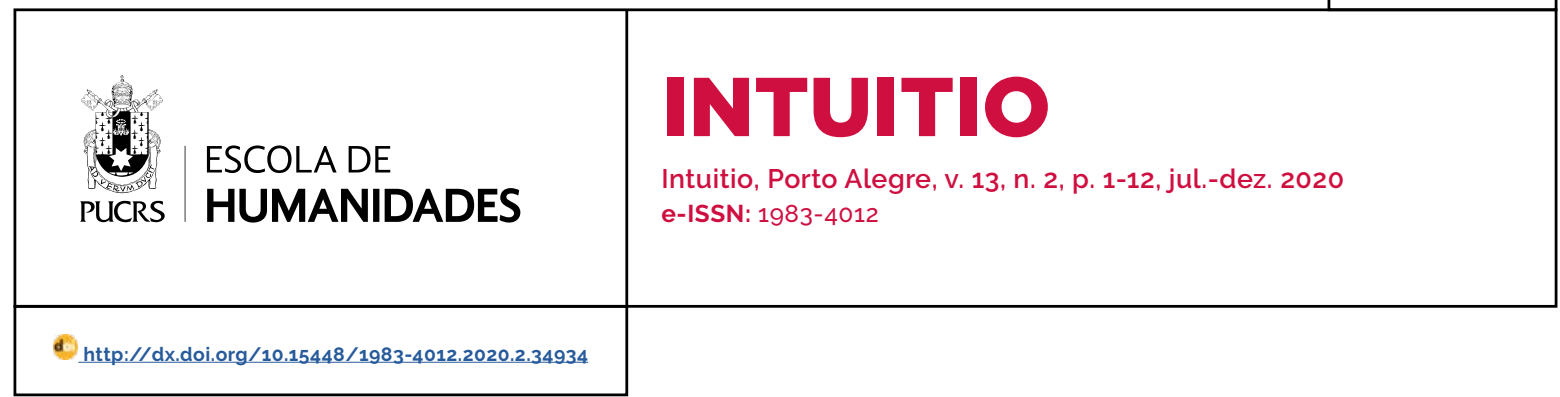

SEÇÃO: ARTIGO

\title{
A sociedade aberta e sua proveniência grega, segundo a perspectiva de Popper
}

The open society and your greek provenience, according to Popper's perspective

\author{
Daniel Mota Vieira ${ }^{1}$ \\ orcid.org/0000-0001-5431-0846 \\ dmv95.ufrrj@gmail.com
}

Recebido em: 20/7/2019

Aprovado em: $8 / 9 / 2020$

Publicado em: 19/2/2021

\begin{abstract}
Resumo: De acordo com a visão de Karl Popper (1902-1994), quando a nova fé que dava sustentação ao humanitarismo começara a se firmar na Grécia, eclodiu a tensão da civilização. Tal reação era acompanhada de fatores como o apelo à tradição, a defesa de velhas virtudes e da velha religião. Desdobrando a visão popperiana, mostramos como esse contexto influenciou a interpretação da política imperialista ateniense por parte do historiador Tucidides. Tomada como oficial, a interpretação tucidideana carrega as marcas da reação contrária ao movimento que rompeu com o tribalismo e instaurou a Sociedade Aberta, cuja marca está na inauguração de uma nova tradição; onde a fé mágica se dissolve e cede espaço à de desafiar teorias e mitos e discuti-los criticamente. Além disso, vê-se a abertura para a liberdade enquanto dimensão do acessivel. Assim, partindo da análise feita por Rémi Brague da Oração Fúnebre, de Péricles, discorremos acerca da necessidade da coragem para a liberdade. Tendo em vista vivermos inseridos em uma dimensão ontológica contingente, desdobramos também como a importância de uma boa deliberação do curso das ações é importante para os cidadãos imersos no campo da responsabilidade pessoal considerando a noção aristotélica de virtude moral.

Palavras-chave: Tensão da civilização. Sociedade Aberta. Liberdade. Acessibilidade. Virtude moral.
\end{abstract}

Abstract: According to the vision of Karl Popper (1902-1994), when the new faith that gave support to humanitarianism began to establish itself in Greece, the tension of civilization emerged. This reaction was accompanied by such factors as the appeal to tradition, the defense of old virtues and the old religion. Unfolding the Popperian view, we show how this context influenced the interpretation of Athenian imperialist politics by the historian Thucydides. Taken as an official, the Tucididean interpretation carries the marks of the contrary reaction to the movement that broke with tribalism and established the Open Society; whose mark is on the inauguration of a new tradition; where magical faith dissolves and gives way to challenging theories and myths and discussing them critically. In addition, one sees the openness to liberty as a dimension of the accessible. Thus, starting from Rémi Brague's analysis of Pericles' Funeral Oration, we discuss the need for courage for liberty. Given that we live in a contingent ontological dimension, we also show how the importance of a good deliberation of the course of actions is important for the citizens immersed in the field of personal responsibility considering the Aristotelian notion of moral virtue.

Keywords: Tension of civilization. Open Society. Liberty. Acessibility. Moral virtue. 


\section{Introdução}

Os primeiros filósofos gregos tentaram, realmente, entender o que se passava na natureza, no entanto, antes deles, os povos primitivos o faziam por via dos mitos que inventavam. Nesse contexto, pergunta-se Karl Popper (1902-1994): como caracterizar e distinguir a tradição das sociedades primitivas, da transmissão e aceitação acrítica dos mitos, da dos fundadores da nossa tradição cientifica, os filósofos helênicos??

A inovação dos primeiros filósofos, de acordo com Popper, foi terem começado a discussão das narrativas explicativas até então presentes. Ao invés de aceitarem a tradição religiosa como inexorável, passaram a contestá-la e, até mesmo, chegavam a inventar novos mitos para substituírem os tradicionais. Essas novas narrativas não eram repetições ou rearranjos de velhas estórias. O principal fator é que constituiam uma nova tradição: a da adoção da atitude crítica com relação aos mitos (não apenas narrar, ou transmiti-los, mas questioná-los). Popper comenta:

Antes, só havia a tradição de primeira ordem: uma estória era transmitida. Agora, continuava a haver naturalmente uma estória a ser transmitida, mas com ela se comunicava também algo como um texto de acompanhamento: "Passo-te esta tradição, mas deves dizer-me o que pensas dela. Reflete: talvez possas dar-me uma explicação distinta". Essa tradição de segunda ordem era a atitude crítica e analítica: algo novo, que é o fundamental da tradição científica. ${ }^{3}$

Essa tensão entre dogmatismo e atitude critica, que desempenhou papel relevante nas discussões de A lógica da investigação científica, na qual Popper apresentou, pormenorizadamente, os traços principais da racionalidade cientifica, também desempenhou papel importante nas discussões do filósofo austríaco acerca da sociedade aberta e seu arcabouço institucional. ${ }^{4}$

Para criticar uma tradição é preciso que, an- tes, a conheçamos e a compreendamos como tal. ${ }^{5}$ De acordo com o autor, não podemos nos libertar inteiramente da influência de uma tradição: qualquer libertação não passa de mudança de uma tradição para outra. Todavia, é possivel ficarmos livres dos tabus de uma tradição; não repelindo-os de imediato, mas aceitando-os criticamente. Libertar-se de um tabu significa refletir sobre ele, colocá-lo sob análise crítica. De tal maneira, é fundamental que entendamos qual pode ser o significado e a função das tradições de modo geral. O filósofo comenta

Libertamo-nos de um tabu ao refletir sobre
ele, perguntando-nos se devemos aceitá-lo
ou recusá-lo. Para isso, é preciso em primeiro
lugar perceber a tradição claramente; enten-
der de modo geral qual pode ser a função e
o significado das tradições. Por isso o proble-
ma é tão importante que nós, racionalistas
- pessoas prontas a contestar e a criticar tudo,
inclusive, espero, sua própria tradição raciona-
lista. Pessoas capazes de tudo questionar, pelo
menos mentalmente; que não se submetem
cegamente a qualquer tradição.

É com essa perspectiva que Popper, no capítulo 10 de $A$ sociedade aberta e seus inimigos ${ }^{7}$,busca apontar e estudar os passos dos gregos que, segundo o autor, parecem terem sido os primeiros a avançar do tribalismo para o humanitarismo.

Assim, procuraremos expor, de acordo com a sua visão, que à época de Tucidides, a nova fé que dava sustentação ao humanitarismo, começara a se firmar na Grécia, mas ainda sem uma formulação. Nesse cenário, o que poderia ser avistado pela população era uma luta de classes, o medo que os democratas possuíam dos partidários do regime oligárquico e a ameaça de desenvolvimentos revolucionários de grande proporção. A reação a esse contexto conturbado era, portanto, acompanhada de muita coisa: o apelo à tradição, a defesa de velhas virtudes e da velha religião. Tamanha situação explica, de acordo com o filóso-

POPPER, K. R. Rumo a uma teoria racional da tradição. In: POPPER, K. R. Conjecturas e refutações. Tradução de Sérgio Bath. Brasília: Editora da Universidade de Brasília, 1982. p. 147-160

3 Ibidem, p. 153.

${ }^{4}$ SHEARMUR, J. The political thought of Karl Popper. London and New York: Routledge, 1996. Para mais informações sobre a conexão e possiveis tensões entre racionalidade epistemológica, tendo em conta o problema da tradição, e racionalidade política, cf. o capítulo 3 : After the Open Society, especialmente o subcapitulo 'Towards a RationalTheory of Tradition', p. 70-78.

5 POPPER, 1982.

6 Ibidem, p. 149. Destaques do autor.

7 POPPER, K. R. A sociedade aberta e seus inimigos. In: POPPER, K. R. A sociedade aberta e seus inimigos. v.1. Tradução de Milton Amado. Belo Horizonte: Editora Itatiaia; São Paulo: EDUSP, 1974. 
fo, o fato de grandes atenienses, como o próprio Tucidides, ficarem ao lado da reação contrária ao movimento da queda da sociedade tribal.

Tendo em vista também a necessidade da coragem para a liberdade, considerando-se que estamos inseridos, enquanto singularidades irrepetiveis ${ }^{8}$, em uma dimensão ontológica da contingência, desdobraremos como a importância de uma boa deliberação do curso das ações é importante para os cidadãos imersos no campo da responsabilidade pessoal tendo em vista a noção de virtude moral. ${ }^{9}$ Nosso pano de fundo consiste em, sobretudo, evidenciar que a liberdade e seu usufruto é uma honrosa herança que possuímos.

\section{A sociedade fechada e a teoria orgânica do Estado}

Popper compara a primitiva sociedade tribal grega, em seus principais aspectos, a outras sociedades fechadas como as de Polinésios ou Maoris. Todas constituídas por pequenos bandos de guerreiros, que normalmente viviam em postos fortificados e governados por chefes tribais, reis ou por famílias aristocráticas que travavam guerras uns contra os outros, tanto no mar quanto na terra. Sem dúvida, diz o filósofo austríaco, há diferenças entre a sociedade dos gregos e as demais, uma vez que não há uniformidade no tribalismo ou um modo de vida tribal padronizado. No entanto, diz ele, essas sociedades possuem peculiaridades em comum, sendo elas a atitude de caráter mágico ou irracional para com os costumes da vida social e a correspondente rigidez desses costumes.

O principal elemento da atitude mágica para com os costumes sociais é a falta de distinção entre as regularidades corriqueiras ou convencionais da vida social e as encontradas na natureza - muita das vezes acompanhada pela crença de que ambas são impostas aos homens por alguma vontade sobrenatural. Quando Popper refere-se à rigidez do tribalismo, ele não quer dizer que não ocorra mudanças nesse regime, sua intenção é demonstrar que as mudanças são raras e possuem o caráter de conversões religiosas - não têm fundamentos em alguma tentativa racional de melhorar as condições sociais.

Tendo em vista a relativa dificuldade para que essas mudanças ocorram, os tabus regulam e dominam, rigidamente, todos os aspectos da vida. Nenhum problema enfrentado pelos membros da sociedade tribal tem, assim, a equivalência dos problemas morais da sociedade moderna. Ainda que um homem, membro da tribo, necessite de grande heroísmo e paciência para agir de acordo com os tabus estabelecidos, ele raramente se encontrará diante de um impasse sobre como deve agir. O modo reto é sempre ordenado pelas mágicas instituições tribais, que nunca podem ser objetos de avaliação crítica.

Atualmente, os nossos próprios modos de vida ainda não deixam de ser regidos por tabus: alimentares, de polidez etc. No entanto, há diferenças que não podem ser desconsideradas. No meio em que habitamos há, entre as leis do Estado, de um lado, e os tabus que observamos, de outro, um campo sempre ampliado de decisões pessoais, de elevada importância e repleto de problemas e responsabilidades. Nossas decisões podem conduzir à alteração de tabus, e mesmo das leis políticas. A grande diferença para com o modo de vida tribal é, portanto, a possibilidade, aberta, de reflexão racional sobre tais assuntos. Popper observa que:

\begin{abstract}
[...] em nosso próprio tempo, muitos tomamos decisões pessoais relativamente à desejabilidade ou não de nova legislação e de outras alterações institucionais, isto é, decisões baseadas numa avaliação das consequências possiveis e numa preferência consciente por algumas delas. Reconhecemos a responsabilidade pessoal racional. ${ }^{10}$
\end{abstract}

Postas em jogo essas tamanhas diferenças, Popper diz que podemos denominar a sociedade mágica, tribal ou coletivista, como sociedade fechada; enquanto a sociedade em que, em contraposição, está aberto o leque de decisões pessoais

\footnotetext{
Devo essa expressão a Roque Spencer Maciel de Barros (1927-1999).

ARISTÓTELES. Tratado da virtude moral; Ethica Nicomachea l 13 - III 8. Tradução, notas e comentários de Marco Zingano. São Paulo: Odysseus Editora, 2008.

10 POPPER, 1974, p. 188
} 
pode ser denominada aberta ou democrática.

Segue-se que a tentativa grega de superação do estado tribal significa um empreendimento de superar o já apontado isomorfismo entre natureza e convenção. ${ }^{11}$ Destarte, foram os gregos os primeiros a traçar uma distinção entre os costumes humanos, que são de caráter convencional e transitório, e as regularidades da natureza, independentes das idiossincrasias humanas. As leis normativas proibem ou prescrevem certo tipo de comportamento e são passiveis de alteração.

O estado tribal, ao não considerar tamanho contraste, acaba por instituir uma sociedade estática, inexorável, que passa a interpretar, como dissemos, qualquer alteração à altura de uma conversão religiosa. Dessa maneira, a tribo é vista de modo similar a um organismo cujas células funcionam sem se sobrepor umas às outras e ocupam posições rigidamente determinadas pelo metabolismo social. Popper comenta:

\begin{abstract}
Uma sociedade fechada, no seu aspecto mais completo, pode ser justamente comparada a um organismo. A chamada teoria orgânica ou biológica do estado pode ser-lhe aplicada em considerável extensão. Uma sociedade fechada se assemelha a uma horda ou tribo por ser uma unidade semi-orgânica cujos membros são mantidos juntos por laços semi-orgânicos - parentesco, coabitação, participação nos esforços comuns, nos perigos comuns, nas alegrias e aflições comuns. É ainda um grupo concreto de indivíduos concretos, relacionados uns com os outros não só por abstratas relações sociais tais como a divisão do trabalho e o intercâmbio de utilidades, como por concretas relações físicas, tais como o tacto, o olfato, a vista. ${ }^{12}$
\end{abstract}

Portanto, uma sociedade democrática pode, em contraste, tornar-se gradualmente uma "sociedade abstrata". Ela, em considerável extensão, perde o caráter de um grupo concreto ou de um sistema de tais grupos. Popper utiliza-se de um exagero para explicar esse ponto: ele concebe uma sociedade em que os homens, praticamente, nunca se encontram face a face, aonde todos os negócios são conduzidos por indivíduos isolados que se comunicam por via de cartas datilografadas, ou telegramas, e andam em automóveis fechados. Essa sociedade fictícia pode ser rotulada, nas palavras do nosso autor, como "completamente abstrata ou despersonalizada".13

A sociedade moderna se assemelha, em muitos de seus aspectos, a essa versão totalmente abstrata. Ainda que nem sempre viajemos só em automóveis fechados, diz Popper, o resultado é quase o mesmo se assim o fizéssemos. Não estabelecemos qualquer relação pessoal com os demais pedestres quando estamos a caminhar pelas ruas. $O$ fato de ser membro de um sindicato, observa o filósofo austríaco, não significa nada mais que a posse de uma carteirinha de associado e o pagamento de uma contribuição para um secretário desconhecido.

Muitas pessoas vivem em nossa sociedade sem ter nenhum ou poucos contatos pessoais íntimos, vivendo no anonimato, no isolamento, e, por conseguinte, de maneira infeliz uma vez que embora a sociedade tenha se tornado abstrata, a nossa configuração biológica não mudou muito: temos necessidades sociais, precisamos nos inter-relacionar, e isso acaba por ficar à parte. O autor reforça que:

Sem dúvida, nosso quadro, mesmo desta forma,
é altamente exagerado. Nunca haverá, nem
poderá haver uma sociedade completamente
ou mesmo predominantemente abstrata - assim
como não pode haver uma sociedade comple-
tamente ou predominantemente racional. Os
homens ainda formam grupos concretos, têm
contatos sociais concretos de toda espécie, e
tentam satisfazer suas necessidades sociais
emocionais do melhor modo que podem. Mas,
na maior parte, os grupos sociais concretos de
uma sociedade democrática moderna (com
exceção de alguns felizes grupos familiares) são
pobres substitutos, visto como não dão razão a
uma vida comum. E muitos deles não têm qual-
quer função na vida da sociedade em geral. ${ }^{14}$

Outro modo pelo qual tal quadro se mostra exagerado é o fato de ele não conter qualquer das vantagens obtidas com o rompimento das sociedades tribais, mas, apenas, as perdas. As relações pessoais podem surgir onde possam ser livremente estabelecidas ao invés de serem

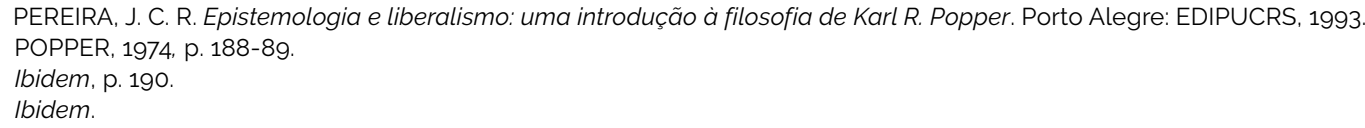


determinadas por laços de sangue, por exemplo. Popper, assim, deixa claro que seu exemplo teve respaldo no intento de contrapor uma sociedade mais abstrata a um grupo social mais concreto. Nossa moderna sociedade democrática funciona por meio de relações abstratas, entre elas a de intercâmbio e cooperação. É com a análise de relações sociais como essas que se ocupa a moderna teoria social e, também, a teoria econômica. ${ }^{15}$

Com esses aspectos, Popper ressalta que a transição da sociedade fechada para a aberta pode ser descrita como "uma das maiores revoluções por que passou a humanidade". ${ }^{16}$ Nesse ponto está o cerne de sua afirmação de que a nossa civilização ocidental procede dos gregos e profundamente deve ter sido sentida essa transição, que, ao olhar popperiano, parece ainda estar no início. ${ }^{17}$ É disso que passaremos a tratar a partir de agora.

\section{0 desmoronamento da sociedade fechada: a abertura para o mundo enquanto dimensão do acessivel}

O desmoronamento da sociedade fechada, na Grécia, deu-se por volta do século VI a.C., tendo como causas principais o aumento da população em meio à classe dirigente de proprietários de terras, que exigiu uma diversificação de funções. ${ }^{18}$ Essa complexificação abalou os alicerces sociais pelo fato de aumentar, entre os socii, os espaços para as dúvidas sobre a maneira correta de proceder. A classe dirigente, como meio de aliviar a pressão, buscou uma solução orgânica, através da criação de cidades filiadas, que se revelou desastrosa ao permitir o contato com culturas distintas. A referida explosão demográfica, no entanto, não é suficiente para explicar a queda do tribalismo: o comércio marítimo se revelou ainda mais importante. Popper observa que:

Talvez a mais poderosa queda da sociedade
fechada tenha sido o desenvolvimento das
comunicações maritimas e do comércio. O
estreito contacto com outras tribos é suscep-
tível de minar o sentimento de necessidade
com que são encaradas as instituições tribais;
e o comércio, a iniciativa comercial, parece ser
uma das poucas formas pelas quais a iniciativa
individual e a independência podem afirmar-se
mesmo numa sociedade em que ainda preva-
lece o tribalismo. Estas duas coisas, navegação
e comércio, tornaram-se as principais carac-
teristicas do imperialismo ateniense, tal como
se desenvolveu no século $V$ antes de Cristo. ${ }^{19}$

Desse modo, de acordo com o filósofo, a falência da sociedade fechada e a transição para a sociedade aberta, ou democrática, ocasiona a "tensão da civilização". ${ }^{20}$ Essa tensão é resultante da ideia de que todas as coisas se encontram em um fluxo desordenado. ${ }^{21}$ Todas as instituições humanas, antes inabaláveis, tornam-se indeter-

15 O problema de uma sociedade composta por individuos atomizados, a referida sociedade abstrata, põe em relevo a dificuldade de compreender autênticos laços sociais num mundo despido de qualquer valor intrínseco conferido à tradição. Não vejo como superar o problema apostando em formas progressivas de cooperação e intercâmbio entre os individuos, que se consideram como singularidades irrepetiveis. Ao contrário, pesar o indivíduo de forma não abstrata exige uma forma de compreendê-lo mediante a sua inserção concreta na sociedade, à medida que se torna progressivamente capaz de tomar decisões e responder por encargos sociais. A atualidade da noção de virtude está precisamente aqui. Não temos como deliberar ou sermos nós mesmos a não ser nos aplicando a certas práticas e nos reconhecendo em certos bens compartilhados, o que não significa que não se possa também criticá-los ou que não se possa refletir sobre eles. O que acontece é que, enquanto agentes, não temos como nos posicionar "livremente" em relação aos bens compartilhados. Mesmo o esforço crítico já é orientado para um aprimoramento das práticas e instituições. Em certo sentido, para lançar mão de um exemplo moderno, vejo que Kant pensa desse modo quando fala em "uso público da razão". De todo modo, vejo aqui um ponto de ruptura com o modo de vida tribal, pois o lugar de cada um já estaria previamente decidido antes da constituição do agente, ou seja, antes de nos tornarmos capazes de agir agindo. O excelente trabalho de OLIVA, Alberto. Conhecimento e liberdade: individualismo x coletivismo. Porto Alegre: EDIPUCRS, 1994. consiste em um estudo dos fundamentos filosóficos de um liberalismo ético-politico. O autor faz uma critica cerrada ao holismo ou coletivismo e defende o primado do individuo ao mesmo tempo em que rechaça o individualismo naturalista ou a visão de que o individuo seja como um átomo que, apenas por si, é capaz de causar reações ou modificações na estrutura social. 16 POPPER, 1974, p. 191.

17 O surgimento da filosofia pode ser interpretado como um resultado da queda sociedade fechada e de suas crenças mágicas; configurando-se como uma tentativa de substituir a perdida fé mágica por uma fé racional. O debate crítico, com o despontar da filosofia, mostra-se como uma alternativa à elaboração e recepção passiva dos mitos (/bidem.).

18 PEREIRA, 1993

19 POPPER, 1974, p. 192-93

20 PEREIRA, 1993

21 Popper acentua que foi Heráclito o filósofo que descobriu a ideia de mudança. A ênfase sobre a mudança e, especialmente, na mudança na vida social, é uma característica relevante não apenas da filosofia heraclitiana, mas do historicismo em geral. A transitoriedade das coisas, incluindo os regimes de governo e as instituições, é uma verdade que se torna, entre os teóricos historicistas, mister assinalar. Todavia, em Heráclito evidencia-se, de acordo com o filósofo austriaco, uma das caracteristicas menos recomendáveis do historicismo: um enfoque exagerado na mudança ligado à crença em uma inexorável lei do destino. Esse contorno faz da doutrina da mudança de Heráclito uma expressão do sentimento de "estar à deriva", marco da referida "tensão da civilização". Assim, o pensador de Éfeso apresenta-se como um dos adversários pioneiros da edificação da sociedade aberta. Para mais informações, cf. POPPER, 1974. capítulos 1 e 2. 
minadas. Conforme já vimos, a sociedade aberta desprende-se do caráter de um grupo concreto ou de um sistema de grupos concretos e as relações entre os cidadãos, antes firmadas em laços orgânicos tribais, cedem espaço a uma fria impessoalidade e, até mesmo, a confiança no comportamento moral se dissolve. Todo o peso da responsabilidade moral encontra-se, portanto, conforme vemos plenamente em nosso tempo, nos ombros do sujeito.

Parte dessa tensão está em nos tornarmos cada vez mais dolorosamente conscientes das grandes imperfeições de nossa vida, das imperfeições pessoais e das institucionais, do sofrimento evitável, do desperdício, da desnecessária hediondez e, ao mesmo tempo, do facto de não ser impossivel fazer algo com relação a tudo isso, mas de que tais melhoramentos seriam tão árduos de realizar quanto são importantes. Essa consciência aumenta a tensão da responsabilidade pessoal, de carregar a cruz de ser humano. ${ }^{22}$

Rémi Brague atenta ao fato de que as proezas que Péricles (494 a.C. - 429 a.C.) credita à sua cidade, Atenas, consistem, sobretudo, na instituição de um possivel novo; dando à terra e ao mar a nova dimensão da acessibilidade. ${ }^{23}$ Em outras palavras, amplia-se, com a derrocada do tribalismo, o domínio sobre o qual se pode exercer a ação humana.

O que Tucidides nos descreve, segundo o autor francês, é a audácia pela qual a acessibilidade é, de forma ampla, considerada o critério daquilo que é. Com a acessibilidade de tudo, estamos, portanto, vendo a diferença entre o sagrado e o profano em ruínas e nesse ponto, segundo Brague, está "uma das origens longínquas do "desencantamento moderno do mundo". ${ }^{24}$ Um trecho da Oração Fúnebre, reproduzida pelo historiador grego, nos clarifica bem esse contexto:

Compelimos todo o mar e toda a terra a dar passagem à nossa audácia, e em toda parte plantamos monumentos imorredouros dos males e dos bens que fizemos. Esta, então, é a cidade pela qual estes homens lutaram e morreram nobremente, considerando seu dever não permitir que ela thes fosse tomada; é natural que todos os sobreviventes, portanto, aceitem de bom grado sofrer por ela. ${ }^{25}$

Atenas, com essa abertura, torna-se um mercado para o qual afluem os produtos de todo mundo conhecido. Temos aqui uma integração, progressiva, de toda terra ao mercado mundial. Segundo Brague, podemos ver, na obra de Tucídides, uma elaboração primária das características civilizacionais que seriam preservadas, de forma espontânea, para a modernidade. $O$ autor comenta:

\begin{abstract}
Procurar em Tucidides, desse modo, a forma embrionária do mundo moderno é um empreendimento perfeitamente legítimo, desde que seja evitado um erro ainda mais grave que o anacronismo, o de não dar à nossa própria modernidade toda a amplitude que lhe cabe. por não se ter apreendido em profundidade suficiente o lance inaugural grego de que ela é um eco - o impulso sobre o qual ela continua e que pode se ocultar na própria obviedade que ela possui para nós. ${ }^{26}$
\end{abstract}

Assim, mais premente que todas as conquistas do regime imperialista é a luz sob a qual aparecem as coisas que, posteriormente, poderão ficar sob controle, isto é, dentro da dimensão da acessibilidade. Logo, Brague, analisando a exposição de Tucidides, diz que a terra e o mar são os dois elementos manifestos ao uso e úteis, porque assim manifestos. Não há outra consideração sobre eles, a não ser do ponto de vista do uso que lhes é feito. Destarte, o uso comporta uma capacidade intrínseca de descrever o alcançável; e é, também, nessa medida, que devemos entender a "inutilidade do cidadão apolítico" declarada por Péricles em sua Oração Fúnebre: uma vez que esse cidadão se exclui da Pólis, ele se exclui do lugar onde se manifestam terra e mar e todo o restante de coi-

\footnotetext{
22 POPPER, 1974, p. 215-16.

BRAGUE, R. O mundo livre. In Introdução ao mundo grego: estudos de história da filosofia. Tradução de Nicolás Nyimi Campanário. São Paulo: Edições Loyola, 2007. p. 35-63.

24 Ibidem, p. 46.

25 TUCIDIDES. História da Guerra do Peloponeso. Prefácio de Hélio Jaguaribe. Tradução do grego por Mário da Gama Kury. $4^{a}$ ed. Brasilia: Editora da Universidade de Brasília; São Paulo: Imprensa oficial do Estado de São Paulo, 2001. p. 112.

26 BRAGUE, 2007, p. 46-47.
} 
sas dado como "útil". ${ }^{27}$ A manifestidade da terra e do mar está desprovida de evidência puramente teórica, e coincide, de forma estrita, com a ótica da dominação. Dessa forma, Brague realça que é preciso compreender aquilo que, até mesmo, no louvor de Péricles, consistia na exaltação de uma realidade meramente econômica.

Dentro dessa exposição, temos duas noções cuja importância de desmembrá-las se faz muito importante: tlèmosunèe tolmè. A tolmé, traduzida costumeiramente por "ousadia", não diz respeito, de forma exclusiva, ao real presente, mas está ligada ao que é possivel dentro do futuro. A tlèmosuné, por outro lado, abarca somente o que ocorre no agora. Brague diz que podemos situar esses dois conceitos opondo menos o ativo ao passivo, supondo a clareza desses conceitos, e mais o real ao possivel. A tlèmosunè está imbricada, portanto, ao real em sua separação do possivel, enquanto a tolmè enfrenta o real em sua união com o possivel, inclusive o futuro. Nesse momento, o autor aponta um paradoxo: o real não priva, em nada, o possivel de seu estatuto de possivel, mas o aviva. O possivel separado do real é aquilo que podemos imaginar, muito caro à produção poética ${ }^{28}$, no entanto, estamos aqui diante de inimagináveis possibilidades do real, inseridos, como ser-aí, em uma dimensão ontológica da contingência. Por conseguinte, a própria realidade da presença do possivel enquanto possivel garante a sua possibilidade e uma dimensão presente no real é justamente a do perigo, demandando a coragem.

A coragem, segundo Brague, é necessária para a liberdade a fim de defender essa última da sujeição e tal combate, tem, nas palavras do autor, a "condição suprema que se prefira a liberdade à própria vida".29 A coragem, enquanto tolmé, está no fundo da liberdade e, nessa medida, ela acolhe o possivel enquanto tal antes que este se degrade no realizável, disposto a virar real e negociável como uma moeda de troca. A liberdade, configura-se, assim, como uma relação com o perigo:

Não há liberdade sem perigo nem perigo sem
liberdade, pois a própria liberdade é um perigo:
em um dos raros momentos do pensamento
grego clássico em que a liberdade aparece sob
a figura, mais familiar aos modernos, da liber-
dade de escolha - um mito -. Platão chama o
momento em que a alma deve escolher sua vida
entre todos os destinos possiveis que se ofere-
cem a ela de "o risco total para o homem" [.....$^{30}$

Popper diz que a História da Guerra do Peloponeso, de Tucidides, analisada por Brague, é uma prova dessa transição. ${ }^{31}$ Ele observa que, ao lermos Tucidides, devemos ter em mente que embora o historiador não pertencesse à ala extremada das organizações oligárquicas atenienses, que estavam a conspirar durante toda guerra junto ao inimigo, ele era, por certo, membro do partido oligárquico, não sendo nem amigo do povo ateniense, o demos, nem das políticas imperialistas da, nas palavras de Péricles, "Escola da Hélade".

De acordo com o filósofo austríaco, a colocação de Tucidides como um antidemocrata torna-se clara quando consideramos a descrição que o historiador faz do império ateniense e do modo pelo qual tal império era odiado pelos vários estados gregos. Tucidides diz que o domínio de Atenas sobre o seu império era percebido, por todas as tribos gregas, como uma tirania. Ao descrever a opinião pública quando a Guerra do Peloponeso eclodiu, mostrou-se benévolo, diz Popper, com Esparta e incisivo em relação ao imperialismo ateniense:

O sentimento geral dos povos estava fortemente ao lado dos Lacedemônios, pois asseguravam que eles eram os libertadores da Hélade. Cidades e indivíduos mostravam-se ansiosos por auxiliá-

\footnotetext{
27 "Ver-se á em uma mesma pessoa ao mesmo tempo o interesse em atividades privadas e públicas, e em outros entre nós que dão atenção principalmente aos negócios não se verá falta de discernimento em assuntos políticos, pois olhamos o homem alheio às atividades públicas não como alguém que cuida apenas de seus próprios interesses, mas como um inútil" (TUCIDIDES, 2001, p. 110).

28 Nesse ponto, segundo Brague, Tucídides opõe, de um lado, a hyponoia do poeta, a busca do possivel pelo espírito (nous) entregue a si mesmo, e, de outro, o trabalho do historiador, não menos "hyponoético", que procura o possível dentro do real. Dessa maneira, tanto a poesia quanto a história se relacionam com o possivel, mas não consideram o mesmo aspecto dele. Na produção poética, o possível é construído pelo espírito, enquanto na história é concebido de modo prático, na verdade dos fatos - estes concebidos enquanto obras (BRAGUE, 2007).

29 Ibidem, p. 53.

30 Ibidem, p. 53-54

31 POPPER, 1974
} 
-los... e a indignação geral contra os Atenienses era intensa. Alguns anelavam ser libertados de Atenas, outros temiam cair sobre o seu domínio.32

Popper observa que o mais interessante centra-se no fato de que esse julgamento do historiador sobre o império ateniense tornou-se, mais ou menos, o julgamento da maior parte dos historiadores. ${ }^{33}$ No entanto, tais afirmativas de Tucidides, de acordo com o filósofo, são apenas expressões do ponto de vista antidemocrático e que muitos fatos registrados pelo historiador grego, como na passagem supracitada, mostram que os intentos de Esparta possuiam "popularidade" não entre os povos da Grécia e sim entre os oligarcas.

É importante atentarmos que a intenção de Popper, como ele bem ressalta, não é defender tudo o que os atenienses fizeram na edificação de seu império e ele não deseja fazer a defesa, se ocorreram, de ataques injustificados ou brutais. O filósofo austríaco também não esquece que a democracia ateniense ainda se baseava em um regime escravocrata; no entanto, ele crê que a exclusividade e autossuficiência tribalista só podiam ser superadas por alguma forma de imperialismo. Além disso, reforça que algumas medidas imperialistas introduzidas por Atenas eram, antes de tudo, liberais. ${ }^{34}$

Tal opinião, favorável ao imperialismo ateniense, deve ser sustentada, consoante a exposição de Popper, por via de uma comparação com os métodos espartanos de tratar dos negócios estrangeiros. O alvo definitivo que dominava a política de Esparta, tendo em vista a tensão da civilização, era paralisar qualquer mudança. Ele aponta os seis princípios da política espartana:

1) Proteção do tribalismo detido: fechar a porta a todas as influências estrangeiras que pudessem pôr em perigo a rigidez dos tabus tribais. - 2) anti-humanitarismo: fechar a por- ta, mais especialmente, a todas as ideologias igualitárias, democráticas e individualistas. - 3) Autarquia: ser independente do comércio. -4) Anti-universalismo ou particularismo: sustentar a diferenciação entre a própria tribo e as outras: não se misturar com inferiores. - 5) Dominação: submeter e escravizar os vizinhos. - 6) Não se expandir demais: "a cidade só deve crescer enquanto puder fazê-lo sem prejudicar sua unidade", e, especialmente, sem arriscar-se à introdução de tendências universalistas..$^{35}$

Analisando essas seis tendências principais, Popper vê que elas concordam fundamentalmente com o totalitarismo moderno com exceção da sexta. O filósofo diz que o totalitarismo moderno parece ter inclinações imperialistas, no entanto esse "imperialismo totalitário" não tem elementos de tolerante universalismo e suas ambições de âmbito mundial surgem contra a vontade de seus lideres.

Dois fatores mostram-se responsáveis por isso: todas as tiranias possuem a inclinação de justificar sua existência em nome da salvação do Estado ou do "povo" de seus inimigos (sendo um grupo de inimigos eliminados, sempre outro irá surgir). O segundo fator é levar a cabo os pontos 2 e 5 . O humanitarismo que, de acordo com 2 , deve ser um ponto fora da curva, tornou-se tão universal que a fim de combatê-lo eficientemente deve-se travar uma luta contra ele em todo o mundo. No entanto, diz o filósofo austríaco, o mundo tornou-se tão pequeno, as fronteiras se tornaram tão mais tênues ${ }^{36}$, que todos hoje se tornaram vizinhos e, assim, todos também devem ser dominados e escravizados. Nada poderia ter sido mais perigoso, na antiguidade, para Esparta e seus simpatizantes, do que o imperialismo ateniense, com sua tendência a agregar as cidades gregas e, até mesmo, tornar-se um império universal do homem. ${ }^{37}$ Consoante trecho da Oração Fúnebre seguido do comentário do nosso autor:

\footnotetext{
TUCIDIDES, II, 9 apud POPPER, 1974, p. 195.

POPPER, 1974

"Um exemplo muito interessante é o fato de que Atenas ofereceu, em 405 A.C., à sua aliada, a ilha jônica de Samos, 'que os Samianos passassem a ser Atenienses de então em diante; e que ambas as cidades fossem um só estado; e que os habitantes de Samos ordenassem seus negócios internos como lhes aprouvesse, mantendo suas leis'" (Ibidem, p. 197).

35 Ibidem, p. 198

36 A sociedade aberta e seus inimigos foi publicada em 1945. Se levarmos em conta, hoje, o crescimento implacável das mídias digitais constataremos que elas não apenas eliminaram as fronteiras, em termos de comunicação, mas criaram múltiplos espaços de influência política e social.

37 O discurso de Péricles na Oração Fúnebre, de acordo com Popper, mostra-se não apenas como um programa, mas também como um ataque. Esse ataque dirige-se não apenas contra o tribalismo detido de Esparta, mas também contra o que o filósofo austriaco denominou de "anel" ou "elo" totalitário interno, firmado em Atenas. Platão, um de seus representantes, elaborou, inclusive, uma paródia indisfarçada da oração de Péricles: o diálogo intitulado Menexeno ou a Oração Fúnebre. Dentro dos limites deste trabalho, não trataremos dos ataques de Popper à filosofia platônica.
} 
Somos também superiores aos nossos adversários em nosso sistema de preparação para a guerra nos seguintes aspectos: em primeiro lugar, mantemos nossa cidade aberta a todo o mundo e nunca, por atos discriminatórios, impedimos alguém de conhecer e ver qualquer coisa que, não estando oculta, possa ser vista por um inimigo e ser-lhe útil. Nossa confiança se baseia menos em preparativos e estratagemas que em nossa bravura no momento de agir. $\mathrm{Na}$ educação, ao contrário de outros que impõem desde a adolescência exercícios penosos para estimular a coragem, nós, com nossa maneira liberal de viver, enfrentamos pelo menos tão bem quanto eles perigos comparáveis. ${ }^{38}$

Essas tendências atraíam os sentimentos de muitos homens e sua popularidade deu origem a um movimento que, embora dirigido e utilizado pelos Espartanos e seus amigos oligarcas para seus próprios fins, deve ter incorporado muitos homens retos, mesmo em Atenas. Do lema desse movimento: "Voltemos ao estado de nossos antepassados", ou "Voltemos ao antigo estado paterno", deriva-se o termo "patriota". Quase não vale a pena insistir em que as crenças populares entre aqueles que defendiam esse movimento "patriótico" foram grosseiramente desfiguradas pelos mesmos oligarcas, que não vacilaram em entregar sua própria cidade ao inimigo com a esperança de obter sua ajuda contra os democratas. ${ }^{39}$

Popper diz que as palavras supracitadas, de Péricles, não constituem apenas um elogio a Atenas: expressam o verdadeiro espírito de uma Grande Geração. ${ }^{40}$ A Oração Fúnebre faz-se equivalente a um programa político de um magistral individualista igualitário, de acordo com o filósofo austríaco. ${ }^{41} \mathrm{De}$ um democrata que compreendia muito bem não poder a democracia exaurir-se no ingênuo princípio de que "o povo" ou "a maioria" deve governar, mas que deve centrar-se na fé na razão e no humanitarismo. ${ }^{42} \mathrm{Em}$ meio a todo contexto conflituoso em que foi formulado, o discurso pericleano é, também, uma manifes- tação de verdadeiro patriotismo, de justa ufania por uma cidade que não apenas se tornara a "Escola da Hélade", mas que estendeu o seu legado espiritual para a posteridade.

Em suma, pode-se dizer, de acordo com a exposição popperiana, que a revolução política e espiritual, que começara com a derrocada do tribalismo grego, alcançou seu auge no século V com a eclosão da Guerra do Peloponeso. Tal movimento desenvolveu-se, portanto, em violenta guerra de classes e, ao mesmo tempo, num conflito entre as duas principais cidades gregas. O florescer da liberdade, que traz consigo a fé no homem, na justiça e na razão humana, garantiu-se sob um alto preço.

\section{Considerações finais: a defesa da Sociedade Aberta e consideração da virtude moral enquanto cidadãos imbricados em uma dimensão ontológica da contingência.}

Ao longo deste trabalho, considerando as observações popperianas concernentes aos aspectos de uma teoria racional da tradição, foi-nos possivel mostrar como o movimento grego de superação da sociedade tribal significou uma iniciativa para vituperar a isomorfia entre natureza e convenção. Dessa maneira, os gregos foram os primeiros a estabelecer uma distinção entre os costumes humanos, de cunho convencional e transitório, e as regularidades da natureza, que se encontram à parte das nossas idiossincrasias.

Desse ponto, o Estado tribal, ao estatuir uma sociedade estática, desconsidera tamanho contraste e, assim, qualquer alteração em seu interior

\footnotetext{
TUCIDIDES, 2001, p. 110

POPPER, 1974, p. 199

Ibidem.

41 Embora o individualismo moderno tenha ai a sua origem, a ênfase no mérito e na virtude, o fato de nenhum indivíduo, entre os mortos, ter sido nomeado, como mostra Nicole Loraux, evidencia que o indivíduo não possui, entre os atenienses de Péricles, nenhuma proeminência sobre a cidade como um todo. A missão da cidade não era a de garantir segurança e proteger a liberdade dos cidadãos. Ou seja, Péricles não era um liberal, ainda que o liberalismo possa encontrar a sua origem nos ideais por ele sustentados (LOURAX, N. A invenção de Atenas. Tradução de Lilian Valle. Rio de Janeiro: Editora 34, 1994).

42 De acordo com Popper, o princípio de uma politica democrática é elaborar, desenvolver e proteger instituições politicas que se destinam a evitar a tirania. Por um lado, esse principio não implica que sejamos obrigados a implantar instituições de tal natureza que sejam infaliveis ou impecáveis ou, mesmo, que todas as medidas tomadas por um governo democrático sejam corretas. No entanto, subentende-se, a partir do mesmo principio, que até mesmo a adoção de uma política ruim é preferivel à tirania. A partir dessa ótica, a teoria da democracia não se estriba no princípio ingênuo de que "a maioria" deve governar; pelo contrário, os vários métodos de controle do governo democrático, tais como eleições ou governo representativo, não devem ser considerados nada além do que salvaguardas institucionais que foram bem testadas. Eles são sempre passiveis de aprimoramento e capazes de apontar caminhos para que isso ocorra. Para mais informações, cf. o capitulo 7. v.1, de POPPER, 1974, especialmente as seções I e II.
} 
é encarada à altura de uma conversão religiosa. A teoria orgânica do Estado concebe as sociedades, ou tribos, como células que funcionam sem se sobrepor umas às outras uma vez que ocupam posições rigidamente determinadas pelo metabolismo social.

Dessa forma, o movimento rumo à Sociedade Aberta estribava-se em uma nova fé que dava sustentação ao humanitarismo, mas que, no entanto, ainda se encontrava sem formulação. Nesse contexto, a população avistava a luta de classes, o medo dos democratas em relação aos partidários do regime oligárquico e a ameaça de grandiosos desenvolvimentos revolucionários. Vivia-se a tensão da civilização e a reação a esse sentimento era acompanhada do apelo à tradição, da defesa das velhas virtudes, da velha religião e ufanismo. Nesse periodo conturbado, podemos entender o fato de grandes atenienses, como Tucidides, terem se posicionado favoravelmente à reação que buscava apartar esse movimento de abertura.

Logo, desdobramos a visão popperiana, que se pretende contrária à mais usual ${ }^{43}$, mostramos como a reação à tensão da civilização influenciou a interpretação pericleana da política imperialista ateniense. Assim, conforme as reflexões de Rémi Brague acerca da necessidade da coragem para a liberdade, enquanto abertura para o acessivel, mostramos que a tolmé, traduzida usualmente por "ousadia", enfrenta o real em sua união com o possivel. Vimos, que a partir dessa abordagem surge o seguinte paradoxo: o real não furta o estatuto de possivel do possivel, ao contrário, o aviva. O possivel, enquanto separado do real, é aquilo que podemos imaginar, frequente no campo da produção poética; entretanto, estamos diante de inimagináveis possibilidades do real, inseridos em uma dimensão ontológica da contingência.

Consequentemente, a própria realidade da presença do possivel garante a sua possibilidade; e uma dimensão presente no âmbito do real é justamente a do perigo, demandando a coragem. Tendo em vista o viver em uma dimensão contingente, uma boa deliberação do curso das nossas ações faz-se de elevada importância. Para a questão, a abordagem aristotélica da virtude moral é de muito considerável interesse. ${ }^{44}$

Aristóteles, no II livro de sua Ética Nicomaquéia, observa que nenhuma virtude moral se engendra em nós por natureza, uma vez que nada do que existe na natureza habitua-se a ser de modo diverso. ${ }^{45}$ Tomando a pedra e o fogo como notáveis exemplos, o estagirita assevera que a primeira, que naturalmente se move para baixo, não se habituaria, de modo algum, a mover-se para cima, ainda que alguém tentasse habituá-la lançando-a diversas vezes para cima; da mesma forma para com o fogo: movendo-se naturalmente para cima, não está em nosso cabedal fazer com que ele se mova para baixo. ${ }^{46}$ No que concerne às virtudes morais, elas não se engendram nem pela nem contra a natureza, mas pelo fato de que somos capacitados a recebê-las e a aperfeiçoá-las pelo hábito.

Assim, adquirimos as virtudes tendo-as primeiramente exercitado. Tal situação assemelha-se ao trabalho artístico, de acordo com Aristóteles: o que é necessário aprender para fazer, aprendemos fazendo. Logo, os homens tornam-se construtores construindo casas, os pianistas tocando piano e assim por diante. Do mesmo jeito, nos tornamos justos praticando atos justos; temperantes, praticando atos temperantes; corajosos, praticando atos corajosos. Por conseguinte, é também do praticar que se corrompe tanto a virtude quanto a arte. Daí a necessidade de que as ações exprimam certas qualidades e agir de um modo ou outro desde jovem, ainda mais em termos de aperfeiçoar-se quanto às virtudes, é de elevada importância. Conforme passagem:

[...] com efeito, do praticar a citara surgem tanto os bons quanto os maus citaristas. Os construtores e todos os demais artesãos analogamente:

\footnotetext{
43 "Assim como os filósofos acham dificil libertar-se dos pontos de vista de Platão, também os historiadores se prendem aos de Tucídides" (Ibidem, p. 196).

44 Para uma análise geral da influência da filosofia de Aristóteles na cultura ocidental moderna, cf. o interessante livro de SANTOS

Francisco de Araújo. A emergência da modernidade: atitudes, tipos e modelos. Petrópolis, RJ: Vozes, 1990.

45 ARISTÓTELES. 2008.

46 Aqui temos a teoria do "lugar natural". Exposta na Física.
} 
por construir bem, tornar-se-ão bons construtores; por construir mal, maus construtores. Se não fosse assim, ninguém precisaria do mestre, mas todos nasceriam bons ou maus. Assim também se passa com as virtudes: agindo nas transações entre os homens, tornam-se uns justos; outros, injustos; agindo nas situações de perigo e habituando-se a temer ou a ter confiança, tornam-se uns corajosos; outros, covardes. ${ }^{47}$

A partir desse aspecto, faz-se importante mencionar a questão da escolha deliberada. Segundo Aristóteles, ela concerne àquelas coisas que estão em nosso poder. Por escolhermos, deliberadamente, coisas boas ou más que somos de certa qualidade. Assim, esse tipo de escolha é louvado pelo fato de ser subordinado ao que se deve mais do que pelo fato de ser reta. ${ }^{48}$ Logo, ela está à parte do agir irrefletidamente, confrontando os apetites e configurando-se de suma importância dentro da dimensão ontológica da contingência em que vivemos 49

Destarte, deliberar diz respeito às coisas que ocorrem até em certa frequência e que, no entanto, é obscuro ou indefinido como resultarão. ${ }^{50} \mathrm{O}$ estagirita diz que por essa razão nos cercamos de conselheiros; quando descrentes de nós mesmos quanto a discernir o que fazer. Ele observa, com muita acuidade, que:

Deliberamos não sobre os fins, mas sobre as coisas que conduzem aos fins. Com efeito, nem o médico delibera se há de curar, nem o orador se há de convencer, nem o político se há de fazer uma boa constituição, nem ninguém mais delibera sobre o fim, mas, tendo posto um fim, investigam como e através de que o obterão; e, parecendo ocorrer através de vários meios, investigam através de qual mais rápida e belamente ocorrerá; sendo produzido por um único meio, investigam como ocorrerá através disto e este através de que meio, até chegarem à primeira causa, que é a última na ordem da descoberta. ${ }^{11}$

Portanto, deliberando sobre os meios para atingir os nossos objetivos, chegamos à conclusão de que os princípios das nossas ações estão em nós. ${ }^{52}$ Escolher deliberadamente relaciona-se, dessa maneira, com o desejo deliberativo do que está ao nosso alcance, uma vez que julgando em função de termos deliberado, desejamos consoante a deliberação. ${ }^{53}$

Logo, deliberar sobre os melhores meios para atingir os fins que desejamos faz-se de suma importância no âmbito da Sociedade Aberta. ${ }^{54}$ Enquanto singularidades irrepetiveis, somos invioláveis em nossa dignidade ética, benemerentes de sermos tratados sempre como fim e nunca como meio. Deliberar, inclusive abrir-se ao Outro, ouvir o que ele tem a dizer sobre as nossas pretensões ou postulações de conhecimento, é de relevância fundamental não apenas para o progresso científico, mas para uma convivência harmônica. De acordo com Popper, a vida de Sócrates foi um magnânimo exemplo de fé na Sociedade Aberta. ${ }^{55}$ Com seu destemor, seu senso de humor, simplicidade e modéstia, o "moscardo de Atenas" mostrou que um homem pode morrer não apenas por conta de seu destino, pela fama ou por outras coisas desta espécie, mas, também, em prol da liberdade do pensamento crítico e pelo respeito

47 Ibidem, p. 42. 1103b8-17.

48 Ele difere-se do opinar: a opinião divide-se em verdadeira e falsa; e pode ser sobre qualquer coisa, inclusive sobre o que não está em nosso poder. Logo, os que melhor deliberam não estão no mesmo patamar dos que melhor opinam. Uns, embora opinem bem, nada garante que escolherão por vício o que não devem (Ibidem.).

49 Aristóteles diz que os animais irracionais e as crianças compartilham do voluntário, mas não da escolha deliberada (Ibidem)

50 Popper diz que é típico de todas as situações sociais haver individuos que fazem coisas, que querem coisas ou que têm determinados objetivos em vista. Na medida em que essas pessoas agem no sentido em que desejam, alcançando os fins propostos, nenhum problema surge para as ciências sociais - exceto o de saber se esses objetivos e impulsos podem ter explicação social: por certas tradições, por exemplo. Os problemas peculiares às ciências sociais só aparecem em função do desejo, que possuimos, de conhecer as consequências não desejadas das nossas ações - especialmente as que almejamos evitar. Assim, desejamos prever não só as consequências diretas do que fazemos, mas também as indiretas e não desejadas. A razão disso se estriba no fato de termos curiosidade científica ou porque estamos a fim de enfrentá-las para que não se tornem muito graves. Isso, por sua vez, engendra novas ações e, por conseguinte, novos efeitos imprevistos (POPPER, 1982).

51 ARISTÓTELES, 2008.

52 Difere-se dos atos forçados, cujos principios são exteriores a nós (Ibidem)

53 Importante ressaltar que toda escolha deliberada é manifestamente voluntária, mas que nem todo voluntário é objeto de escolha deliberada (Ibidem)

54 A questão é que a escolha deliberada não incide sobre os fins, mas supõe, em certo sentido, que os fins já estejam postos. Como estes não são naturais, precisam ser incorporados pelo hábito. É aqui que a diferença entre a perspectiva liberal e a de Aristóteles se impõe. O indivíduo precisa ser educado para assim desejar corretamente. Não há nenhum lugar para se respeitar a liberdade individual vista de maneira abstrata.

55 POPPER, 1974 
a si mesmo, sem relação com o sentimento de auto importância ou com a pieguice.

Por conseguinte, uma vez que depositemos confiança em nossa razão e façamos uso dos nossos poderes de crítica - capacidade essa que podemos colocar dentro da dimensão da acessibilidade - sentindo o peso das responsabilidades pessoais e, por via delas, a responsabilidade de contribuir com a expansão do conhecimento, o retorno ao estado de submissão, que constitui a magia tribal, mostra-se inviável. ${ }^{56}$ Quanto mais tentarmos regressar à era histórica do tribalismo, diz o filósofo austríaco, mais seguramente chegaremos à instauração de medidas e instituições repressivas, tais como a inquisição, a polícia secreta ou o banditismo romantizado. Suprimindo a razão e a verdade, aniquilamos tudo o que é humano. ${ }^{57}$ Tendo em vista a dimensão ontológica contingente, na qual estamos inseridos, devemos utilizar ao máximo a razão para planejar tanto a segurança, quanto a liberdade.

\section{Referências}

ARISTÓTELES. Tratado da virtude moral IEthica Nicomachea / 13 - III 8]. Tradução, notas e comentários de Marco Zingano. São Paulo: Odysseus Editora, 2008.

BRAGUE, R. O mundo livre. In: Introdução ao mundo grego: estudos de história da filosofia. Tradução de Nicolás Nyimi Campanário. São Paulo: Edições Loyola, 2007. p. 35-63.

LOURAX, N. A invenção de Atenas. Tradução de Lilian Valle. Rio de Janeiro: Editora 34, 1994.

OLIVA, A. Conhecimento e liberdade: individualismo x coletivismo. Porto Alegre: EDIPUCRS, 1994.

PEREIRA, J. C. R. Epistemologia e liberalismo: uma introdução à filosofia de Karl R. Popper. Porto Alegre: EDIPUCRS, 1993.

POPPER, K. R. A sociedade aberta e seus inimigos. Tradução de Milton Amado. Belo Horizonte: Editora Itatiaia; São Paulo: EDUSP, 1974. v.1.
POPPER, K. R. Rumo a uma teoria racional da tradição In: Conjecturas e refutações. Tradução de Sérgio Bath. 2. ed. Brasilia: Editora da Universidade de Brasília, 1982. p. 147-160.

SANTOS, F. A. A emergência da modernidade: atitudes, tipos e modelos. Petrópolis, RJ: Vozes, 1990.

SHEARMUR, J. The political thought of Karl Popper. London and New York: Routledge, 1996.

TUCIDIDES. História da Guerra do Peloponeso. Tradução do grego por Mário da Gama Kury. 4. ed. Brasília: Editora da Universidade de Brasília; São Paulo: Imprensa Oficial do Estado de São Paulo, 2001.

\section{Daniel Mota Vieira}

Mestrando em Filosofia na Universidade Federal Rural do Rio de Janeiro (UFRRJ).

\section{Endereço para correspondência}

Daniel Mota Vieira

Km 07, Zona Rural, BR-465

Seropédica - RJ

$23890-000$

\footnotetext{
56 A pressuposição do realismo metafísico fundamenta as ideias-base da epistemologia popperiana: testabilidade, corroboração, verdade etc. e sua ideia de liberdade corresponde a um conceito ético fortemente relacionado à tradição racionalista grega. Conforme observa Júlio César Rodrigues Pereira: "[...] o primado da experiência não nos conduziu a uma concepção instrumentalista de teoria, devido ao fato do modelo de racionalidade popperiano não ser restrito a uma lógica vazia, mas ao contrário por compreender a ciência como uma manifestação da autonomia e da liberdade do pensamento, capaz de explicar a realidade e libertar o homem de crenças obsoletas e repressivas. Em que pese o caráter formal da ciência, ela é um discurso capaz de conectar com a realidade sócio-política e promover a liberdade" (PEREIRA, 1993).

57 "Não podemos retornar às bestas. Mas, se quisermos permanecer humanos, então só existe um caminho, o caminho para a sociedade aberta" (POPPER, 1974, p. 217).
} 